\title{
Immunohistochemical Expression of PD-L1 and MDR1 in Breast Tumors: Association with Clinico- Pathological Parameters and Treatment Outcome
}

\section{Gisha Rose Antony}

Regional Cancer Centre Thiruvananthapuram

\section{Paul Augustine}

Regional Cancer Centre Thiruvananthapuram

TP Sulfath

Regional Cancer Centre Thiruvananthapuram

\section{BL Ajeesh}

Regional Cancer Centre Thiruvananthapuram

Jayasree K

Regional Cancer Centre Thiruvananthapuram

KM Jagathnath Krishna

Regional Cancer Centre Thiruvananthapuram

Lakshmi S ( $\nabla$ rcc.lakshmi@gmail.com )

Regional Cancer Centre Thiruvananthapuram https://orcid.org/0000-0003-1916-0015

\section{Research Article}

Keywords: Breast cancer, PD-L1, MDR1, Immunohistochemistry, Chemoresistance, Prognosis

Posted Date: January 20th, 2022

DOI: https://doi.org/10.21203/rs.3.rs-1248526/v1

License: (c) (i) This work is licensed under a Creative Commons Attribution 4.0 International License. Read Full License 


\section{Abstract}

Antitumor immune evasion is a hallmark for the development and progression of cancer. Tumor cells adopt various mechanisms to escape the host immune system recognition. One such mechanism is the over expression of programmed death ligand (PD-L1), a negative T cell regulatory molecule. Because PDL1 overexpression causes resistance to chemotherapeutic response in many cancers, herein we explored the relationship between PD-L1 and multidrug resistance protein MDR1 in breast cancer. Immunohistochemical evaluation of PD-L1 and MDR1 proteins in 194 breast cancer tissue samples were carried out. The relationship between PD-L1 and MDR1 expression on cancer cells with clinicopathological factors and prognosis was investigated. IHC showed a significant correlation between PD-L1 and MDR1 expression on tumor cells. Increased PD-L1 expression was also associated with lymph node status and tumor grade of the patient. Our results also revealed that the expression of PD-L1 and MDR1 was higher in TNBC subtype compared to other breast cancer subtypes. Therefore a better understanding of the molecular mechanism through which PD-1/PD-L1 pathway contribute to the chemoresistance might bring forth the prognostic significance of PD-L1 and selection of patients who may benefit from immunotherapy.

\section{Introduction}

Breast cancer (BC) is the most frequently diagnosed malignancy and the most common cause of cancerrelated mortality in women worldwide [1]. Although there is progress in reducing the mortality rate, many existing treatments benefit only a subset of breast cancer patients [2]. BC is a heterogeneous disease, characterized by the expression of key proteins that are major drug targets and used to stratify patients to a particular treatment given alongside standard surgery, chemotherapy, and radiotherapy protocols. Triple negative breast cancer (TNBC) that are negative for hormone receptor ER and PR, and the Her-2 oncogene expression, do not respond to hormone therapy and Her-2 targeted therapy. Chemotherapy is the only treatment option available for these patients and has the poorest prognosis among BC subtypes [3]. The immune system plays an integral role in cancer development and consequently offers novel targeted therapies. Immune checkpoint inhibition represents major breakthrough in the treatment of many malignancies including breast cancer. As breast cancer is also immunogenic, targeting the immune system is a promising strategy for its treatment $[4,5]$.

The programmed death receptor-1 (PD-1) and its ligand, PD-L1 are gradually recognized as powerful targets to boost tumor-directed cytotoxic T-cell function. Interaction of PD-1 with its ligand induces a negative signal that limits T cell activity. Therefore, PD- 1 and its ligands play an essential role in the ability of cancer cells to evade the immune system [6]. An essential strategy to prevent immune escape is to block PD-1/PDL-1 interaction. PD-L1 is expressed on a variety of normal cells, immune cells as well as malignant cells. PD-L1 expression level on tumor cells plays a crucial role in treatment response.

Increased expression of PD-L1 is associated with poor prognosis in the majority of tumor types. However, in various tumors including breast cancer, high PDL1 expression can also have a favorable prognostic response to PD-1/PD-L1 inhibition therapy [7]. 
Chemoresistance or multidrug resistance (MDR) is the major obstacle in the treatment of cancer and one of the major causes of treatment failure in many carcinomas. One underlying mechanism is the cellular overexpression of P-glycoprotein (P-gp), a 170KDa protein expressed by the MDR1 gene [8]. P-gp acts as an efflux pump for various anticancer drugs $[9,10]$. The P-gp overexpression in cancer cells has become a therapeutic target for evading multi-drug resistance. However, the regulation of MDR in cancer cells remains poorly understood $[11,12]$. Chemotherapy treatment is known to up-regulate PD-L1 expression on tumors, which is associated with poor prognosis in Non-small-cell lung carcinoma (NSCLC) patients [13]. It has been reported that in breast and prostate cancer, interaction of PD-L1 with PD-1 increases the chemotherapeutic resistance via ERK and mTOR phosphorylation. Also, blocking PD-1 or PD-L1 independently resulted in inhibition of PD-1 mediated chemoresistance [14, 15]. PD-1/PD-L1 interaction activates PI3K/AKT and MAPK/ERK pathway to induce MDR1 expression in cancer cells which eventually leads to chemoresistance [16].

Since PD1/PD-L1 axis stands as a powerful target for immunotherapy in many malignancies, in the present study we have analyzed the expression of PD-L1 and MDR1 proteins in 194 breast cancer tissue samples, representing different molecular subtypes by immunohistochemistry. We have also looked into the correlation between PD-L1 and MDR1 expression, their association with various clinicopathological features, including overall and disease-free survival.

\section{Materials And Methods}

\section{Patient Cohort}

A total of 194 samples from patients diagnosed with locally advanced breast carcinoma at the Regional Cancer Centre in the period of January 2012 to December 2013 were included in the study. The patient's clinical information, including age, clinical stage at diagnosis, histopathology grade, Lymph node (LN) selection, and pathologic response was collected from the medical records of the hospital. The inclusion criteria were (1) all female breast cancer patients operated at the regional cancer center, Thiruvananthapuram during the above-mentioned period, and (2) where patient data was completely available. Patients with metastatic disease at presentation were excluded from our study. Follow-up data of all patients were collected till August 2021 for detection of local recurrence and distant metastasis. Survival data was confirmed with telephonic confirmation apart from case records.

\section{Immunohistochemistry (IHC)}

Tissue sections from formalin-fixed, paraffin-embedded ( $4 \mu \mathrm{m}$ thick) breast tissues and adjacent normal breast samples were first subjected to Hematoxylin and Eosin staining (H\&E staining) to confirm whether they were tumor and normal samples and to ensure that the number of tumor and normal cells was sufficient for IHC analysis. IHC analysis was carried out using standard procedures. Briefly, serial sections were deparaffinized in xylene and hydrated through graded alcohol. Endogenous peroxidase activity was blocked using $0.3 \% \mathrm{H}_{2} \mathrm{O}_{2}$ in methanol for 30 min followed by antigen retrieval by boiling in 1X EDTA 
buffer ( $\mathrm{pH}$ 9.0) for 15 minutes. The slides were then cooled and non-specific binding sites were blocked by incubating with $3 \%$ bovine serum albumin (BSA) for 20 minutes in a humidified chamber at room temperature. The sections were then incubated overnight at $4^{\circ} \mathrm{C}$ with primary antibodies specific for PDL1 (anti-PD-L1, E1L3 XP, rabbit monoclonal antibody Cell Signaling Technology, 1:200) and MDR-1 proteins (anti-MDR1, mouse monoclonal antibody, Santa Cruz Biotechnology, 1:400). Negative controls were incubated with $1 \%$ BSA in TBS. The bounded primary antibody was detected by the addition of a secondary antibody conjugated with horseradish peroxidase polymer (HRP) and diaminobenzidine (DAB) substrate using PolyExcel HRP/DAB IHC detection kit (PathnSitu) according to the manufacturer's instructions. The sections were then counterstained with hematoxylin, dehydrated through graded alcohol, cleared in xylene, and mounted using distyrene, plasticizer (tricresyl phosphate), and xylene (DPX; Merck) mountant. The expression of PD-L1 and MDR1 was evaluated on all tumor cells. A positive stain was defined as the presence of membrane staining, either strong or weak in each tumor cells [17]. For each section, both intensity of membrane staining (scored as 0 no staining, $1+$ weak, $2+$ moderate, and $3+$ strong) and the percentage of positive neoplastic cells were recorded. The overall result of staining was recorded as negative $(\leq 1 \%)$ and positive $(\geq 1 \%)$. Images of PD-L1and MDR1 expression were obtained by EVOS imaging system (Thermofisher Scientific).

\section{Co-expression analysis of PD-L1 and MDR1 genes in breast cancer patients using TCGA dataset}

The TCGA breast cancer patient data (1097 cases) were obtained from UCSC XENA data browser (https://xena.ucsc.edu/). The RNA sequencing data was used to measure the level of gene expression as transcripts per million reads (TPM). The relationship between PD-L1 expression and the MDR1 gene was investigated.

\section{Statistical analysis}

All the statistical analyses were performed using the SPSS statistics software version 11. Appropriate descriptive statistics (mean, SD, range, frequency, percentage) were used to summarize the data. The statistical significance between the two categorical groups were determined by Chi-square test or Fisher's exact test as appropriate. Spearman correlation analysis was used to explore the correlation between PDL1 and MDR1 gene expression. All statistical tests were two-sided. Kaplan-Meier survival curves were generated to estimate the survival probabilities and log-rank test were used to find the difference in survival between PD-L1 and MDR1 positive and negative groups. Disease-Free Survival (DFS) was defined from date of surgery to the date of recurrence, death or last follow-up. Overall Survival (OS) was calculated from the date of first diagnosis to either date of death or the last date of follow-up. P-value $\leq 0.05$ was considered to be statistically significant.

\section{Results}

The study group included a total of 194 breast tissue samples representing molecular subtypes; ER+/PR+/Her2+, ER+/PR+/Her2-, ER-/PR-/Her2+ and ER-/PR-/Her2- (TNBC). Patient and tumor characteristics for the entire study population are shown in Table1. 
Table 1

Clinico-pathological characteristics of patients.

\begin{tabular}{|c|c|c|c|}
\hline \multicolumn{2}{|l|}{ Variables } & \multirow{2}{*}{$\begin{array}{l}\text { Number } \\
50.61(10 .\end{array}$} & Percentage \\
\hline \multirow[t]{2}{*}{ Age } & Mean (SD) & & 67) \\
\hline & Range & $23-80$ & \\
\hline \multirow[t]{2}{*}{ Category } & TNBC & 102 & 52.6 \\
\hline & Others & 92 & 47.4 \\
\hline \multirow[t]{4}{*}{ Type of surgery } & MRM & 153 & 78.9 \\
\hline & BCS & 34 & 17.5 \\
\hline & $A C$ & 3 & 1.5 \\
\hline & RE WE & 4 & 2.1 \\
\hline \multirow[t]{3}{*}{ Histology } & IDC & 189 & 97.4 \\
\hline & ILC & 1 & 0.5 \\
\hline & Others & 4 & 2.1 \\
\hline \multirow[t]{6}{*}{ pT Stage } & 0 & 29 & 14.9 \\
\hline & I & 53 & 27.3 \\
\hline & II & 91 & 46.9 \\
\hline & III & 9 & 4.6 \\
\hline & IV & 4 & 2.1 \\
\hline & Tx & 8 & 4.2 \\
\hline \multirow[t]{4}{*}{ pN Stage } & 0 & 111 & 57.2 \\
\hline & I & 50 & 25.8 \\
\hline & II & 22 & 11.3 \\
\hline & III & 11 & 5.7 \\
\hline \multirow[t]{2}{*}{ pM Stage } & Negative & 193 & 99.5 \\
\hline & Positive & 1 & 0.5 \\
\hline \multirow[t]{3}{*}{ Grade } & II & 23 & 11.9 \\
\hline & III & 170 & 87.6 \\
\hline & IV & 1 & 0.5 \\
\hline LVI & Negative & 32 & 16.5 \\
\hline
\end{tabular}




\begin{tabular}{|c|c|c|c|}
\hline \multirow[t]{2}{*}{ Variables } & & Number & Percentage \\
\hline & Positive & 162 & 83.5 \\
\hline \multirow[t]{2}{*}{ ECE } & Negative & 178 & 91.8 \\
\hline & Positive & 16 & 8.2 \\
\hline \multirow[t]{2}{*}{ PNI } & Negative & 182 & 93.8 \\
\hline & Positive & 12 & 6.2 \\
\hline \multirow[t]{2}{*}{ NACT } & No & 120 & 61.9 \\
\hline & Yes & 74 & 38.1 \\
\hline \multirow[t]{2}{*}{ cPR } & No & 32 & 16.5 \\
\hline & Yes & 162 & 83.5 \\
\hline \multirow[t]{2}{*}{ Adjuvant chemo } & No & 73 & 37.6 \\
\hline & Yes & 121 & 62.4 \\
\hline \multirow[t]{2}{*}{ Adjuvant RT } & No & 43 & 22.2 \\
\hline & Yes & 151 & 77.8 \\
\hline \multirow[t]{4}{*}{ Stage } & I & 42 & 21.6 \\
\hline & II & 71 & 36.6 \\
\hline & III & 55 & 28.4 \\
\hline & IV & 26 & 13.4 \\
\hline
\end{tabular}

\section{Immunohistochemical evaluation of PD-L1 and MDR1 proteins in breast cancer subtypes}

The expression of PD-L1 and MDR1 was analyzed by IHC and the results were recorded based on the intensity of the staining reaction as shown in Figure 1. Out of 194 samples evaluated, the TNBC subtype showed higher PD-L1 (53.9\%) and MDR1 (93.13\%) positivity compared to any other subtypes (Table 2). 
Table 2

Distribution of PD-L1 and MDR1 in tissue sections of BC patient samples.

\begin{tabular}{|c|c|c|c|c|c|c|}
\hline Category & $\begin{array}{l}\text { PD-L1 } \\
\text { Expression }\end{array}$ & Number & $\begin{array}{l}\text { Percentage } \\
(\%)\end{array}$ & $\begin{array}{l}\text { MDR1 } \\
\text { Expression }\end{array}$ & Number & $\begin{array}{l}\text { Percentage } \\
\text { (\%) }\end{array}$ \\
\hline \multirow[t]{3}{*}{ TNBC } & PD-L1 Positive & 55 & $53.9 \%$ & $\begin{array}{l}\text { MDR1 } \\
\text { Positive }\end{array}$ & 95 & $93.13 \%$ \\
\hline & \multirow{2}{*}{$\begin{array}{l}\text { PD-L1 } \\
\text { Negative }\end{array}$} & \multirow[t]{2}{*}{47} & \multirow[t]{2}{*}{$46.1 \%$} & MDR1 & \multirow[t]{2}{*}{7} & \multirow[t]{2}{*}{$6.87 \%$} \\
\hline & & & & Negative & & \\
\hline \multirow{4}{*}{$\begin{array}{l}\text { Other } \\
\text { subtypes }\end{array}$} & \multirow[t]{2}{*}{ PD-L1 Positive } & \multirow[t]{2}{*}{37} & \multirow[t]{2}{*}{$40.2 \%$} & MDR1 & \multirow[t]{2}{*}{66} & \multirow[t]{2}{*}{$71.7 \%$} \\
\hline & & & & Positive & & \\
\hline & \multirow{2}{*}{$\begin{array}{l}\text { PD-L1 } \\
\text { Negative }\end{array}$} & \multirow[t]{2}{*}{55} & \multirow[t]{2}{*}{$59.8 \%$} & MDR1 & \multirow[t]{2}{*}{26} & \multirow[t]{2}{*}{$28.3 \%$} \\
\hline & & & & Negative & & \\
\hline Total & & & & & & 194 \\
\hline
\end{tabular}

\section{Correlation between PD-L1 and MDR1 proteins in breast cancer samples}

We then investigated the correlation of PD-L1 expression with MDR1 in our samples. PD-L1 was found to be positive in 92 breast cancer patients (47.4\%). The positive expression of MDR1 was found in 161 cases (83\%). 27 patients (13.9\%) were negative for both PD-L1 and MDR1 expression, 89 patients (45.9\%) were both positive. Four patients (2.0\%) were $\mathrm{PDL}^{+} / \mathrm{MDR}^{-}{ }^{-}$while, seventy-four patients (38.1\%) were PD$\mathrm{L}^{-} / \mathrm{MDR}^{+}$. Together these results show that there is a positive correlation between the expressions of PD-L1 and MDR1 in breast cancer tissues $(r=0.374, p<0.05)$ (Table 3$)$.

Table 3

Correlation of PD-L1 and MDR1 expression in 194 breast cancer tissue samples.

\begin{tabular}{|c|c|c|c|c|c|}
\hline & \multicolumn{2}{|l|}{ MDR1 } & \multirow{2}{*}{$\begin{array}{l}\text { Spearman's correlation } \\
\text { coefficient (r) } \\
\mathbf{0 . 3 7 4}\end{array}$} & \multirow{2}{*}{$\begin{array}{l}\mathrm{p} \text { value } \\
<0.05\end{array}$} \\
\hline & & Negative & Positive & & \\
\hline \multirow[t]{2}{*}{ PD-L1 } & Negative & 27 & 74 & & \\
\hline & Positive & 4 & 89 & & \\
\hline
\end{tabular}

Analysis of 1097 cases of breast cancer patients in TCGA datasets also showed a positive association between PD-L1 and MDR1 ( $r=0.335, p<0.05)$ (Figure 2). 


\section{Association Of Pd-I1 Expression And Mdr1 With Clinicopathological Features}

We next evaluated the association of PD-L1 and MDR1 with clinicopathological features in our patient samples. The expression of PD-L1 was associated with lymph node status $(p=0.053)$ and tumor grade $(p=0.049)$, with increased PD-L1 expression in grade I/II patients compared to grade III/IV. Also, triplenegative breast cancer patients exhibited increased PD-L1 expression compared to any other subtypes ( $p$ $=0.052$ ). No association was found with the patient's age, clinical stage, histology, type of surgery, lymphovascular invasion (LVI), extracapsular extension (ECE), perineural invasion (PNI), patient's response to chemotherapy, radiotherapy, and pathologic complete response (pCR) (Table 4).

Table 4. Association of PD-L1 and clinicopathological features of breast cancer patients. 


\begin{tabular}{|c|c|c|c|c|c|}
\hline Variables & & PD-L1 negative (n) & PD-L1 positive (n) & $\begin{array}{l}\text { Total no. } \\
\text { (n) }\end{array}$ & $\mathrm{p}$ value \\
\hline \multirow[t]{2}{*}{ Age } & $\leq 50$ & $54(50.5 \%)$ & $53(49.5 \%)$ & 107 & \multirow[t]{2}{*}{0.564} \\
\hline & $>50$ & $48(55.2 \%)$ & $39(44.8)$ & 87 & \\
\hline \multirow[t]{2}{*}{ Category } & TNBC & $47(46.1 \%)$ & $55(53.9 \%)$ & 102 & \multirow[t]{2}{*}{$0.052^{*}$} \\
\hline & Others & $55(59.8 \%)$ & $37(40.2 \%)$ & 92 & \\
\hline \multirow[t]{4}{*}{ Type of surgery } & MRM & $84(54.9 \%)$ & $69(45.1 \%)$ & 153 & \multirow[t]{4}{*}{0.451} \\
\hline & BCS & $15(44.1 \%)$ & $19(55.9 \%)$ & 34 & \\
\hline & $A C$ & $2(66.7 \%)$ & 1(33.3\%) & 3 & \\
\hline & RE WE & $1(25 \%)$ & $3(75 \%)$ & 4 & \\
\hline \multirow[t]{3}{*}{ Histology } & IDC & $99(52.4 \%)$ & $90(47.6 \%)$ & 189 & \multirow[t]{3}{*}{0.479} \\
\hline & ILC & 0 & $1(100 \%)$ & 1 & \\
\hline & Others & $3(75 \%)$ & $1(25 \%)$ & 4 & \\
\hline \multirow[t]{6}{*}{ pT } & 0 & $13(44.8 \%)$ & $16(55.2 \%)$ & 29 & \multirow[t]{6}{*}{$0.049^{*}$} \\
\hline & 1 & $24(45.3 \%)$ & $29(54.7 \%)$ & 53 & \\
\hline & II & $51(56.0 \%)$ & $40(44.0 \%)$ & 91 & \\
\hline & III & $3(33.3 \%)$ & $6(66.7 \%)$ & 9 & \\
\hline & IV & $4(100 \%)$ & 0 & 4 & \\
\hline & Tx & $7(87.5 \%)$ & 1(12.5\%) & 8 & \\
\hline \multirow[t]{4}{*}{$\mathrm{pN}$} & 0 & $55(49.5 \%)$ & $56(50.5 \%)$ & 111 & \multirow[t]{4}{*}{$0.053^{*}$} \\
\hline & 1 & $26(52.0 \%)$ & $24(48.0 \%)$ & 50 & \\
\hline & $\|$ & $11(50.0 \%)$ & $11(50.0 \%)$ & 22 & \\
\hline & III & $10(90.9 \%)$ & $1(9.1 \%)$ & 11 & \\
\hline \multirow[t]{2}{*}{ pM } & Negative & 102(51.3\%) & $91(45.7 \%)$ & 193 & \multirow[t]{2}{*}{0.474} \\
\hline & Positive & 0 & $1(100 \%)$ & 1 & \\
\hline \multirow[t]{3}{*}{ Histology Grade } & ॥ & $14(60.9 \%)$ & $9(39.1 \%)$ & 23 & \multirow[t]{3}{*}{0.380} \\
\hline & III & $88(51.8 \%)$ & $82(48.2 \%)$ & 170 & \\
\hline & IV & 0 & $1(100 \%)$ & 1 & \\
\hline LVI & Negative & $94(52.2 \%)$ & $86(47.8 \%)$ & 180 & 0.706 \\
\hline
\end{tabular}




\begin{tabular}{|c|c|c|c|c|c|}
\hline & Positive & $8(57.1 \%)$ & $6(42.9 \%)$ & 14 & \\
\hline \multirow[t]{2}{*}{ ECE } & Negative & $92(51.7 \%)$ & $86(48.3 \%)$ & 178 & \multirow[t]{2}{*}{0.445} \\
\hline & Positive & $10(62.5 \%)$ & $6(37.5 \%)$ & 16 & \\
\hline \multirow[t]{2}{*}{ PNI } & Negative & $95(52.2 \%)$ & $87(47.8 \%)$ & 182 & \multirow[t]{2}{*}{0.771} \\
\hline & Positive & $7(58.3 \%)$ & $5(41.1 \%)$ & 12 & \\
\hline \multirow[t]{2}{*}{ NACT } & No & $57(47.5 \%)$ & $63(52.5 \%)$ & 120 & \multirow[t]{2}{*}{0.078} \\
\hline & Yes & $45(60.8 \%)$ & 29(39.2\%) & 74 & \\
\hline \multirow[t]{2}{*}{ cPR } & No & $90(52.9 \%)$ & $80(47.1 \%)$ & 170 & \multirow[t]{2}{*}{0.558} \\
\hline & Yes & $12(50.0 \%)$ & $12(50.0 \%)$ & 24 & \\
\hline \multirow[t]{2}{*}{ Adjuvant chemo } & No & $43(58.9 \%)$ & $30(41.1 \%)$ & 73 & \multirow[t]{2}{*}{0.184} \\
\hline & Yes & $59(48.8 \%)$ & $62(51.2 \%)$ & 121 & \\
\hline \multirow[t]{2}{*}{ Adjuvant RT } & No & $21(48.8 \%)$ & $22(51.2 \%)$ & 43 & \multirow[t]{2}{*}{0.607} \\
\hline & Yes & $81(53.6 \%)$ & $70(46.4 \%)$ & 151 & \\
\hline \multirow[t]{4}{*}{ Stage } & I & $23(54.8 \%)$ & $19(45.2 \%)$ & 42 & \multirow[t]{4}{*}{0.164} \\
\hline & II & $30(42.3 \%)$ & $41(57.7 \%)$ & 71 & \\
\hline & III & $33(60.0 \%)$ & $22(40.0 \%)$ & 55 & \\
\hline & IV & $16(61.5 \%)$ & $10(38.5 \%)$ & 26 & \\
\hline
\end{tabular}

\section{${ }^{*} \mathrm{p} \leq 0.05$}

The expression of MDR1 was associated with clinical stage $(p=0.018)$ and response to chemotherapy (adjuvant $-\mathrm{p}=0.005$ and neoadjuvant $\mathrm{p}=0.001$ ). In case of MDR1 expression also, TNBC patients exhibited increased expression compared to other subtypes $(p=0.016)$. In addition, patient age was significantly associated with MDR1 expression ( $p=0.035)$, in particular, showing significantly higher expression in patients older than 50 years. However, we could not find any association with tumor node metastasis, grade, histology, type of surgery, LVI, ECE, PNI, pCR, and radiotherapy response of the patient (Table 5).

Table 5. Association of MDR1 and clinicopathological features of breast cancer patients. 


\begin{tabular}{|c|c|c|c|c|c|}
\hline Variables & & MDR1 negative (n) & MDR1 positive (n) & $\begin{array}{l}\text { Total no. } \\
\text { (n) }\end{array}$ & $p$ value \\
\hline \multirow[t]{2}{*}{ Age } & $\leq 50$ & $22(20.6 \%)$ & $85(79.4 \%)$ & 107 & \multirow[t]{2}{*}{$0.035^{*}$} \\
\hline & $>50$ & $10(11.5 \%)$ & 77(88.5\%) & 87 & \\
\hline \multirow[t]{2}{*}{ Category } & TNBC & $7(6.9 \%)$ & 95(93.1\%) & 102 & \multirow[t]{2}{*}{$0.016^{*}$} \\
\hline & Others & $25(27.2 \%)$ & $67(72.8 \%)$ & 92 & \\
\hline \multirow[t]{4}{*}{ Type of surgery } & MRM & $25(16.3 \%)$ & 128(83.7\%) & 153 & \multirow[t]{4}{*}{0.691} \\
\hline & BCS & $6(17.6 \%)$ & $28(82.4 \%)$ & 34 & \\
\hline & $A C$ & $1(33.3 \%)$ & $2(66.7 \%)$ & 3 & \\
\hline & RE WE & 0 & $4(100 \%)$ & 4 & \\
\hline \multirow[t]{3}{*}{ Histology } & IDC & $31(16.4 \%)$ & 158(83.6\%) & 189 & \multirow[t]{3}{*}{0.598} \\
\hline & ILC & 0 & $1(100 \%)$ & 1 & \\
\hline & Others & $1(25.0 \%)$ & $3(75.0 \%)$ & 4 & \\
\hline \multirow[t]{6}{*}{ pT Stage } & 0 & $6(20.7 \%)$ & 23(79.3\%) & 29 & \multirow[t]{6}{*}{0.889} \\
\hline & 1 & 10(18.9\%) & $43(81.1 \%)$ & 53 & \\
\hline & II & $13(14.3 \%)$ & 78(85.7\%) & 91 & \\
\hline & III & $1(11.1 \%)$ & $8(88.9 \%)$ & 9 & \\
\hline & IV & $1(25.0 \%)$ & $3(75.0 \%)$ & 4 & \\
\hline & Tx & $1(12.5 \%)$ & $7(87.5 \%)$ & 8 & \\
\hline \multirow[t]{4}{*}{ pN Stage } & 0 & 19(17.1\%) & $92(82.9 \%)$ & 111 & \multirow[t]{4}{*}{0.459} \\
\hline & I & $8(16.0 \%)$ & $42(84.0 \%)$ & 50 & \\
\hline & II & $5(22.7 \%)$ & 17(77.3\%) & 22 & \\
\hline & III & 0 & $11(100 \%)$ & 11 & \\
\hline \multirow[t]{2}{*}{ pM Stage } & Negative & $31(16.1 \%)$ & 162(83.9\%) & 193 & \multirow[t]{2}{*}{0.165} \\
\hline & Positive & $1(100 \%)$ & 0 & 1 & \\
\hline \multirow[t]{3}{*}{ Grade } & II & $6(26.1 \%)$ & 17(73.9\%) & 23 & \multirow[t]{3}{*}{0.356} \\
\hline & III & $26(15.3 \%)$ & 144(84.7\%) & 170 & \\
\hline & IV & 0 & $1(100 \%)$ & 1 & \\
\hline
\end{tabular}




\begin{tabular}{|c|c|c|c|c|c|}
\hline \multirow[t]{2}{*}{ LVI } & Negative & $29(90.6 \%)$ & $3(9.4 \%)$ & 32 & \multirow[t]{2}{*}{0.706} \\
\hline & Positive & 151(93.2\%) & $11(6.8 \%)$ & 162 & \\
\hline \multirow[t]{2}{*}{ ECE } & Negative & $30(16.9 \%)$ & 148(83.1\%) & 178 & \multirow[t]{2}{*}{1.000} \\
\hline & Positive & $2(12.5 \%)$ & 14(87.5\%) & 16 & \\
\hline \multirow[t]{2}{*}{ PNI } & Negative & $31(17.0 \%)$ & 151(83.0\%) & 182 & \multirow[t]{2}{*}{0.694} \\
\hline & Positive & 1(8.3\%) & 11(91.7\%) & 12 & \\
\hline \multirow[t]{2}{*}{ NACT } & No & $15(12.5 \%)$ & 105(87.5\%) & 120 & \multirow[t]{2}{*}{$0.001^{* *}$} \\
\hline & Yes & 17(23.0\%) & $57(77.0 \%)$ & 74 & \\
\hline \multirow[t]{2}{*}{ cPR } & No & $27(84.4 \%)$ & $5(15.6 \%)$ & 32 & \multirow[t]{2}{*}{0.558} \\
\hline & Yes & 143(88.3\%) & 19(11.7\%) & 162 & \\
\hline \multirow[t]{2}{*}{ Adjuvant chemo } & No & 18(24.7\%) & $55(75.3 \%)$ & 73 & \multirow[t]{2}{*}{$0.005^{* \star}$} \\
\hline & Yes & 14(11.6\%) & 107(88.4\%) & 121 & \\
\hline \multirow[t]{2}{*}{ Adjuvant RT } & No & $6(14.0 \%)$ & $37(86.0 \%)$ & 43 & \multirow[t]{2}{*}{0.816} \\
\hline & Yes & $26(17.2 \%)$ & $125(82.8 \%)$ & 151 & \\
\hline \multirow[t]{4}{*}{ Stage } & I & $12(28.6 \%)$ & $30(71.4 \%)$ & 42 & \multirow[t]{4}{*}{$0.018^{*}$} \\
\hline & II & $8(11.3 \%)$ & 63(88.7\%) & 71 & \\
\hline & III & $5(9.1 \%)$ & $50(90.9 \%)$ & 55 & \\
\hline & IV & $7(26.9 \%)$ & 19(73.1\%) & 26 & \\
\hline
\end{tabular}

\section{Survival outcome analysis of PD-L1 and MDR1 expression in breast cancer patients}

The overall survival (OS) and disease-free survival (DFS) was then assessed based on the PD-L1 and MDR1 expression. The 6-year overall survival (OS) among the PD-L1 positive patient was 90.5 with a standard error of 3.2. The probability of 6 year OS in PD-L1 negative patients was 77.9 with a standard error of $4.3(p=0.077)$. The 6-year disease-free survival (DFS) among the PD-L1 positive patient was 79.3 with a standard error of 4.4. The probability of 6 year DFS in PD-L1 negative patient was 70.0 with a standard error of $4.7(p=0.204)$ (Table 6 , Figure 3$)$. The 6 year OS among the MDR1 positive patient was 85.3 with a standard error of 2.9, the probability in MDR1 negative patient was 76.4 with a standard error of $7.8(p=0.234)$. The 6 -year DFS among the MDR1 positive patient was 77.8 with a standard error of 3.4, the probability in MDR1 negative patient was 56.9 with a standard error of $9.1(p=0.022)$ (Table 6, Figure 4). We also evaluated the OS and DFS in the TNBC subgroup. However PD-L1 expression was not associated with OS and DFS in TNBC patients (data not shown). 
Table 6. Kaplan-Meier survival estimates (\%) according to PD-L1 and MDR1 expression.

\begin{tabular}{|c|c|c|c|c|c|c|}
\hline \multirow[t]{2}{*}{ Time(Years) } & & & \multicolumn{2}{|l|}{ PD-L1 } & \multicolumn{2}{|l|}{ MDR1 } \\
\hline & & & Positive & Negative & Positive & Negative \\
\hline \multirow{6}{*}{6} & \multirow{3}{*}{ OS } & Survival probability (\%) & 90.5 & 77.9 & 85.3 & 76.4 \\
\hline & & Standard error (\%) & 3.2 & 4.3 & 7.8 & 2.9 \\
\hline & & $p$ value & 0.077 & & 0.234 & \\
\hline & \multirow{3}{*}{ DFS } & Survival probability (\%) & 79.3 & 70.0 & 77.8 & 56.9 \\
\hline & & Standard error (\%) & 4.4 & 4.7 & 3.4 & 9.1 \\
\hline & & $p$ value & 0.204 & & $0.022^{*}$ & \\
\hline
\end{tabular}

${ }^{*} p \leq 0.05$.

\section{Discussion}

Antitumor immune evasion is a hallmark for the development and progression of cancer. Tumor cells adopt various mechanisms to escape the host immune system recognition. One such mechanism is the over expression of PD-L1, a negative T cell regulatory molecule [18]. Recent reports show that the overexpression of PD-L1 upsurges resistance to chemotherapeutic response by tumor cells [19], the mechanism of which is not clear. In this study, to the best of our knowledge, we present novel findings regarding the PD-L1 and MDR1 expression in BC patients from Southern India. Our results showed that PD-L1 expression is high in BC tissues, more specifically in TNBC subtypes and correlates with the expression of MDR1. The PD-L1 positivity in our study population was $47.4 \%$. In previous reports, the expression of PD-L1 in breast cancer varied between $10.4 \%-51 \%$ and many of the studies included the expression of PD-L1 in stromal cells also. These differences may also be due to the use of different techniques in the PD-L1 measurement and the use of different antibodies and IHC scoring systems. However, PD-L1 positivity was $53.9 \%$ in the TNBC group studied which is comparable with other studies [20-24]. Our results also showed that increased PD-L1 expression correlated with lymph node status and tumor grade of the patient, which is consistent with previous reports $[25,26]$. Therefore, positive expression of PD-L1 in breast cancer may be related to tumor progression and maybe considered as a biomarker for predicting the prognosis of BC patients. PD-L1 expression on tumor cells not only negatively regulates T-cell mediated antitumor immunity but also regulates biological behaviors of tumor cells such as proliferation, apoptosis, migration, invasion, and resistance to chemotherapy [27]. Hence PD-L1 status on tumors has also been used as an important indicator for certain immune therapeutic strategies such as anti-PD1 checkpoint blockade [28-30]. Liu et al have shown that the PD-1/PD-L1 interaction activates PI3K/AKT and MAPK/ERK pathway to induce MDR1 expression in cancer cells which eventually leads to chemoresistance [16]. Hence activation of these pathways by PD-1/PD-L1 
interaction may contribute to resistance to chemotherapeutic agents by cancer cells. Our in vitro studies are also in agreement with Liu et als finding that there is a positive correlation between PD-L1 and MDR1 expression in breast cancer (unpublished data). Also, the expression of MDR1 was associated with clinical stage and response to chemotherapy, which is consistent with previous reports [31,32]. TNBC patients exhibited increased expression of MDR1 compared to other subtypes. In addition, patient age was significantly associated with MDR1 expression, showing significantly higher expression in patients older than 50 years. Patients with PD-L1 expression had demonstrated a slightly younger age than those with no PD-L1 expression, although this was not nominally statistically significant. According to the reports of Surakasula et al, BC in India was found to occur in the younger age group as opposed to Western countries [33]. The probability of 6 year overall survival and disease-free survival in PD-L1 positive group was higher than that of PD-L1 negative group in our study cohort though statistically not significant. This is in agreement with studies conducted by other researchers where expression of PD-L1 mRNA or protein was reported to be associated with improved survival especially in basal-like breast tumors $[21,34,35]$. Several studies have reported the association of PD-L1 to a poor prognosis in human malignancies such as NSCLC [36], melanoma [37], and renal cell [38] cancers. A study conducted by Qin et al showed that patients with increased PD-L1 expression had decreased survival compared to PD-L1 no expression group regardless of breast cancer subtype [24]. A recent study also revealed that higher PDL1 expression is associated with a higher PCR rate, which indicates that patients were less likely to be suffering from poor prognosis [39]. These results indicate that the precise stratification of PD-L1 expression on tumors or immune cells of various subtypes of breast cancer could promote improved indulgence of its role on patient outcome.

In our population, the 6 year OS and DFS among MDR1 positive group was also higher than that of MDR1 negative group, which was in conflict with previous reports $[32,40]$. There are conflicting results regarding the role of MDR1 on prognosis [41,42]. The difference among various subsets of population might be due to the heterogeneity of tumors as well as the genetic polymorphism associated with MDR1 gene as reported previously $[43,44]$. Immunotherapy in BC is an emerging concept with encouraging results. In a clinical study done worldwide, it has been shown that the use of a PD-L1 inhibitor in combination with nab-paclitaxel significantly prolonged the disease-free survival of TNBC patients compared to nabpaclitaxel monotherapy group [45]. Hence PD-L1 expression on breast cancer cells may be considered as a predictive biomarker of response to PD-1/PD-L1 checkpoint inhibitors, as not all patients might benefit from these targeted therapies. However, there is no clear harmony on the evaluation method for PD-L1 expression with respect to the selection of antibody clone and the appropriate percentage cutoff level to determine PD-L1 positivity and negativity [46]. Hence testing of PDL-1 using different techniques individually and combined should be standardized in order to make a proper interpretation of the test results.

In conclusion, we have shown that there is a positive correlation between the expressions of PD-L1 and MDR1 in BC tissues, indicating that this might contribute to resistance to chemotherapy. We also demonstrated that the PD-L1 expression is associated with lymph node status and tumor grade of the patient. Cytotoxic drugs are widely used for the treatment of various malignancies, which in part can 
activate the immune checkpoints and may provide immunogenic benefits. Recent study has shown that cytotoxic drugs could induce PD-L1 upregulation through NFKB- dependent pathway in ovarian cancer model [47]. In vitro studies done in our lab have shown that inhibition of PDL1 inhibits MDR1 expression in $\mathrm{BC}$ cells suggesting increased chemotherapeutic efficacy (unpublished data). Therefore a better understanding of the molecular mechanism through which PD-1/PD-L1 pathway contribute to the chemoresistance might bring forth the prognostic significance of PD-L1 and its importance as a therapeutic target. The present retrospective study was done on a small number of samples from a single center. Further studies are needed to overcome these limitations by including larger sample size from multiple centers so as to extrapolate the data to the Indian population.

\section{Declarations}

\section{Acknowledgment}

This work was supported in part by DST-INSPIRE fellowship by Department of Science and Technology (DST), Government of India, New Delhi.

\section{Ethical approval}

Waiver of consent for the study was obtained from Institute Revision Board (IRB) of Regional Cancer Centre-Thiruvananthapuram as this was retrospective study on tissue blocks.

\section{Competing Interest}

The authors declare that they have no competing interests.

\section{Authors Contribution}

All authors contributed to the study conception and design. Material preparation, data collection and experimental work was performed by Gisha Rose Antony, Sulfath TP, Ajeesh BL and Lakshmi S. Clinical samples were provided by Paul Augustine and pathological evaluation was done by Jayasree K. Statistical analysis was performed by Jagathnath Krishna KM. The first draft of the manuscript was written by Gisha Rose Antony and Lakshmi S and all authors commented on previous versions of the manuscript. All authors read and approved the final manuscript.

\section{References}

1. Al-Thoubaity FK. Molecular classification of breast cancer: A retrospective cohort study. Ann Med Surg. 2020;49:44-8.

2. Kaboli PJ, Salimian F, Aghapour S, et al. Akt-targeted therapy as a promising strategy to overcome drug resistance in breast cancer-A comprehensive review from chemotherapy to immunotherapy. Pharmacol Res. 2020;156:104806. 
3. Thike AA, Cheok PY, Jara-Lazaro AR, Tan B, Tan P, Tan PH. Triple-negative breast cancer: clinicopathological characteristics and relationship with basal-like breast cancer. Mod Pathol. 2010;23:123-3.

4. Hartkopf AD, Taran FA, Wallwiener M, et al. PD-1 and PD-L1 immune checkpoint blockade to treat breast cancer. Breast Care. 2016;11:385-90.

5. Bischoff J. Checkpoint inhibitors in breast cancer-current status and future directions. Breast care. 2018;13:27-1.

6. Bailly C, Thuru X, Quesnel B. Combined cytotoxic chemotherapy and immunotherapy of cancer: modern times. NAR Cancer. 2020;2:zcaa002.

7. Liu XI, Guo CY, Tou FF, et al. Association of PD-L1 expression status with the efficacy of PD-1/PD-L1 inhibitors and overall survival in solid tumours: a systematic review and meta-analysis. Int $\mathrm{J}$ Cancer. 2020;147:116-27.

8. Chen J, Lu L, Wang H, Dai L, Zhang P. PKD2 mediates multi-drug resistance in breast cancer cells through modulation of P-glycoprotein expression. Cancer Lett. 2011;300:48-56.

9. Endicott JA, Ling V. The biochemistry of P-glycoprotein-mediated multidrug resistance. Annu Rev Biochem. 1989;58:137-71.

10. Gottesman MM, Fojo T, Bates SE. Multidrug resistance in cancer: role of ATP-dependent transporters. Nat Rev Cancer. 2002;2:48-58.

11. Choi JH, Lim HY, Joo HJ, et al. Expression of multidrug resistance-associated protein1, Pglycoprotein, and thymidylate synthase in gastric cancer patients treated with 5 -fluorouracil and doxorubicin-based adjuvant chemotherapy after curative resection. $\mathrm{Br} J$ Cancer. 2002;86:1578-85.

12. Oue T, Yoneda A, Uehara S, Yamanaka H, Fukuzawa M. Increased expression of multidrug resistance-associated genes after chemotherapy in pediatric solid malignancies. J Pediatr Surg. 2009;44:377-80.

13. Gao L, Guo Q, Li X, et al. MiR-873/PD-L1 axis regulates the stemness of breast cancer cells. EBioMedicine. 2019;41:395-07.

14. Black M, Barsoum IB, Truesdell P, et al. Activation of the PD-1/PD-L1 immune checkpoint confers tumor cell chemoresistance associated with increased metastasis. Oncotarget. 2016;7:10557-67.

15. Han Y, Liu D, Li L. PD-1/PD-L1 pathway: current researches in cancer. Am J Cancer Res. 2020;10:727-42.

16. Liu S, Chen S, Yuan W, et al. PD-1/PD-L1 interaction up-regulates MDR1/P-gp expression in breast cancer cells via PI3K/AKT and MAPK/ERK pathways. Oncotarget. 2017;8:99901-12.

17. Cerbelli B, Pernazza A, Botticelli A, et al. PD-L1 expression in TNBC: a predictive biomarker of response to neoadjuvant chemotherapy?. Biomed Res Int. 2017; 2017:1750925.

18. O'shaughnessy J, Schwartzberg LS, Danso MA, et al. A randomized phase III study of iniparib (BSI201) in combination with gemcitabine/carboplatin (G/C) in metastatic triple-negative breast cancer (TNBC). J Clin Oncol. 2011;29(15_suppl):1007. 
19. Liu H, Tekle C, Chen YW, et al. B7-H3 silencing increases paclitaxel sensitivity by abrogating Jak2/Stat3 phosphorylation. Mol Cancer Ther. 2011;10:960-71.

20. Sabatier R, Finetti P, Mamessier E, et al. Prognostic and predictive value of PDL1 expression in breast cancer. Oncotarget. 2015;6:5449-64.

21. Guo L, Li W, Zhu X, et al. PD-L1 expression and CD274 gene alteration in triple-negative breast cancer: implication for prognostic biomarker. Springerplus. 2016;5:1-8.

22. Mittendorf EA, Philips AV, Meric-Bernstam F, et al. PD-L1 expression in triple-negative breast cancer. Cancer Immunol Res. 2014;2:361-70.

23. Gatalica Z, Snyder C, Maney T, et al. Programmed cell death 1 (PD-1) and its ligand (PD-L1) in common cancers and their correlation with molecular cancer type. Cancer Epidemiol Biomarkers Prev. 2014;23:2965-70.

24. Qin T, Zeng YD, Qin G, et al. High PD-L1 expression was associated with poor prognosis in 870 Chinese patients with breast cancer. Oncotarget. 2015;6:33972-81.

25. Muenst S, Schaerli AR, Gao F, et al. Expression of programmed death ligand 1 (PD-L1) is associated with poor prognosis in human breast cancer. Breast Cancer Res Treat. 2014;146:15-24.

26. Ghebeh H, Barhoush E, Tulbah A, Elkum N, Al-Tweigeri T, Dermime S. FOXP3+ T regs and B7-H1+/PD$1+T$ lymphocytes co-infiltrate the tumor tissues of high-risk breast cancer patients: Implication for immunotherapy. BMC Cancer. 2008;8:1-2.

27. Li J, Chen L, Xiong Y, et al. Knockdown of PD-L1 in human gastric cancer cells inhibits tumor progression and improves the cytotoxic sensitivity to CIK therapy. Cell Physiol Biochem. 2017;41:907-20.

28. Festino L, Botti G, Lorigan P, et al. Cancer treatment with anti-PD-1/PD-L1 agents: is PD-L1 expression a biomarker for patient selection? Drugs. 2016;76:925-45.

29. Udager AM, Liu TY, Skala SL, et al. Frequent PD-L1 expression in primary and metastatic penile squamous cell carcinoma: potential opportunities for immunotherapeutic approaches. Ann Oncol. 2016;27:1706-12.

30. Seiwert TY, Burtness B, Mehra R, et al. Safety and clinical activity of pembrolizumab for treatment of recurrent or metastatic squamous cell carcinoma of the head and neck (KEYNOTE-012): an openlabel, multicentre, phase 1b trial. Lancet Oncol. 2016;17:956-65.

31. Rybarova S, Hodorova I, Hajdukova M, et al. Expression of MDR proteins in breast cancer and its correlation with some clinical and pathological parameters. Neoplasma. 2006;53:128-35.

32. Li W, Song M. Expression of multidrug resistance proteins in invasive ductal carcinoma of the breast. Oncol Lett. 2014;8:2103-09.

33. Surakasula A, Nagarjunapu GC, Raghavaiah KV. A comparative study of pre-and post-menopausal breast cancer: Risk factors, presentation, characteristics and management. J Res Pharm Pract. 2014;3:12-8. 
34. Ali HR, Glont SE, Blows FM, et al. PD-L1 protein expression in breast cancer is rare, enriched in basallike tumours and associated with infiltrating lymphocytes. Ann Oncol. 2015;26:1488-93.

35. Schalper KA, Velcheti V, Carvajal D, et al. In situ tumor PD-L1 mRNA expression is associated with increased TILs and better outcome in breast carcinomas. Clin Cancer Res. 2014;20:2773-82.

36. Azuma K, Ota K, Kawahara A, et al. Association of PD-L1 overexpression with activating EGFR mutations in surgically resected nonsmall-cell lung cancer. Ann Oncol. 2014;25:1935-40.

37. Ott PA, Hodi FS, Robert C. CTLA-4 and PD-1/PD-L1 blockade: new immunotherapeutic modalities with durable clinical benefit in melanoma patients. Clin Cancer Res. 2013;19:5300-09.

38. Thompson RH, Dong H, Kwon ED. Implications of B7-H1 expression in clear cell carcinoma of the kidney for prognostication and therapy. Clin Cancer Res. 2007;13:709s-15s.

39. Pelekanou V, Carvajal-Hausdorf DE, Altan M, et al. Effect of neoadjuvant chemotherapy on tumorinfiltrating lymphocytes and PD-L1 expression in breast cancer and its clinical significance. Breast Cancer Res. 2017;19:1-11.

40. Zhu Z, Wang B, Bi J, et al. Cytoplasmic HuR expression correlates with P-gp, HER-2 positivity, and poor outcome in breast cancer. Tumour Biol. 2013;34:2299-308.

41. Schneider J, Gonzalez-Roces S, Pollán M, et al. Expression of LRP and MDR1 in locally advanced breast cancer predicts axillary node invasion at the time of rescue mastectomy after induction chemotherapy. Breast Cancer Res. 2001;3:183-91.

42. Taheri M, Mahjoubi F. MRP1 but not MDR1 is associated with response to neoadjuvant chemotherapy in breast cancer patients. Dis Markers. 2013;34:387-93.

43. Wang Z, Wang T, Bian J. Association between MDR1 C3435T polymorphism and risk of breast cancer. Gene. 2013;532:94-9.

44. Kim HJ, Im SA, Keam B, et al. ABCB 1 polymorphism as prognostic factor in breast cancer patients treated with docetaxel and doxorubicin neoadjuvant chemotherapy. Cancer Sci. 2015;106:86-3.

45. Schmid P, Adams S, Rugo HS, et al. Atezolizumab and nab-paclitaxel in advanced triple-negative breast cancer. N Engl J Med. 2018;379:2108-21.

46. Gandini S, Massi D, Mandalà M. PD-L1 expression in cancer patients receiving anti PD-1/PD-L1 antibodies: A systematic review and meta-analysis. Crit Rev Oncol Hematol. 2016;100:88-8.

47. Peng J, Hamanishi J, Matsumura N, et al. Chemotherapy induces programmed cell death-ligand 1 overexpression via the nuclear factor-KB to foster an immunosuppressive tumor microenvironment in ovarian cancer. Cancer Res. 2015;75:5034-45.

\section{Figures}




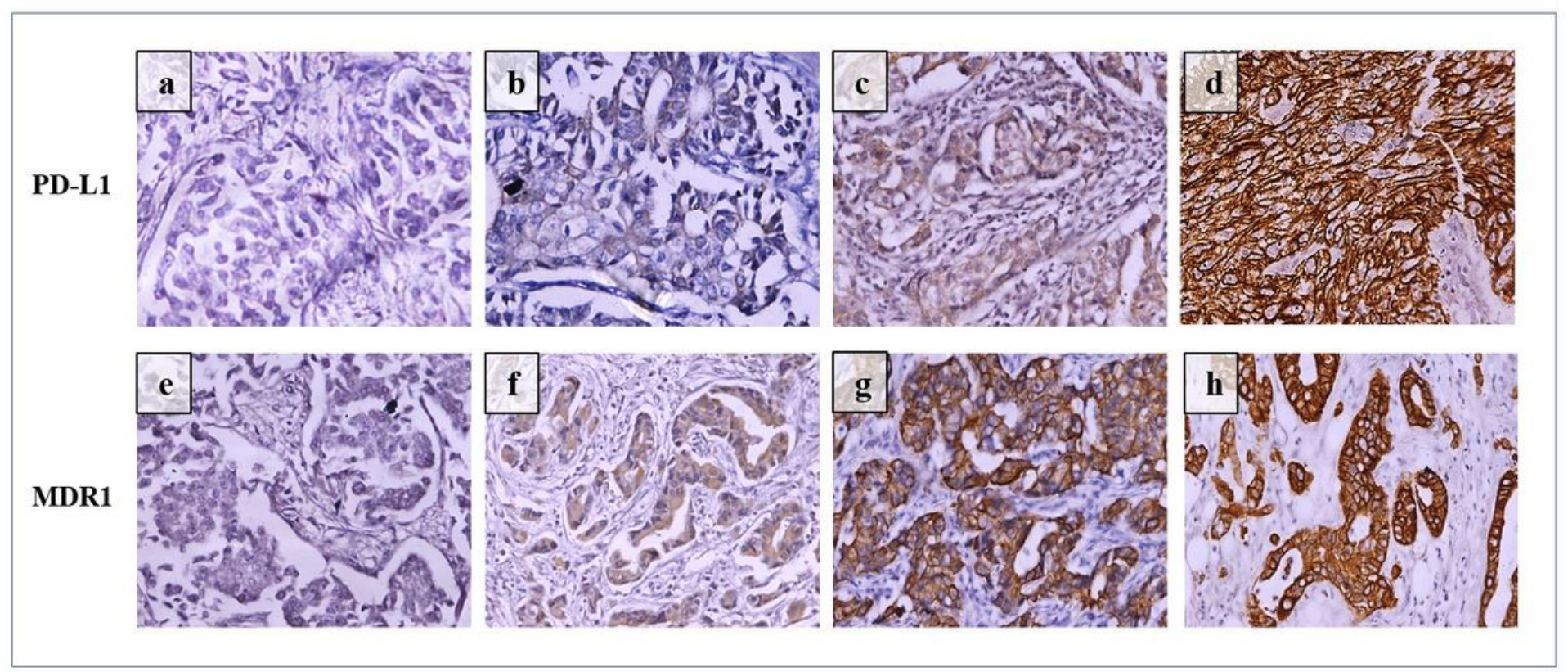

\section{Figure 1}

Representative images of the PD-L1 (a-d) and MDR1 (e-f) immuno-expression of the samples studied: 0, showing no staining; $1+$, showing weak staining; $2+$, showing moderate staining; and $3+$, showing very strong staining $(\mathrm{x} 200)$. 


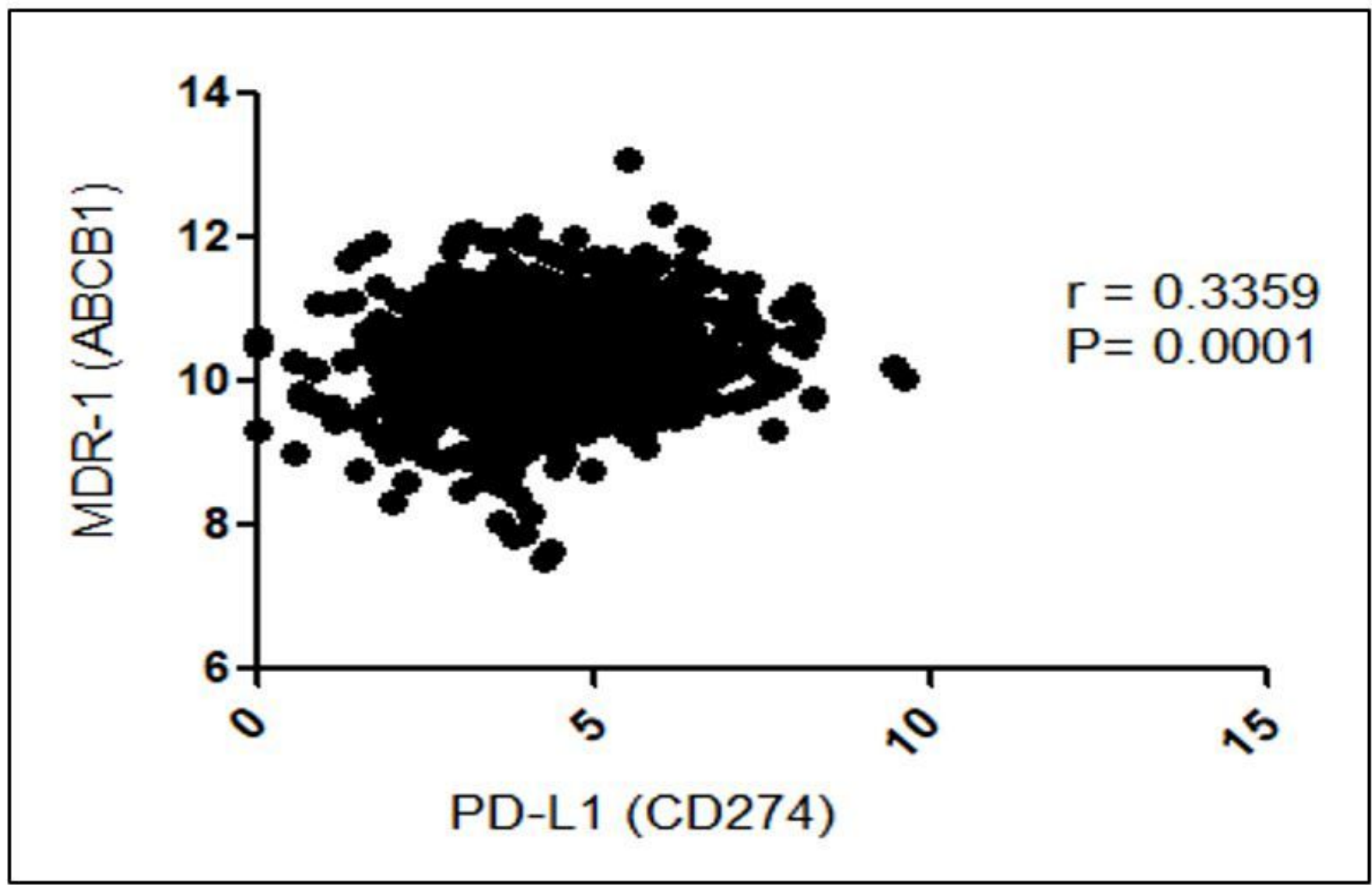

Figure 2

Co-expression analysis of TCGA breast cancer patient dataset showing a positive correlation between PDL1 and MDR1 genes.
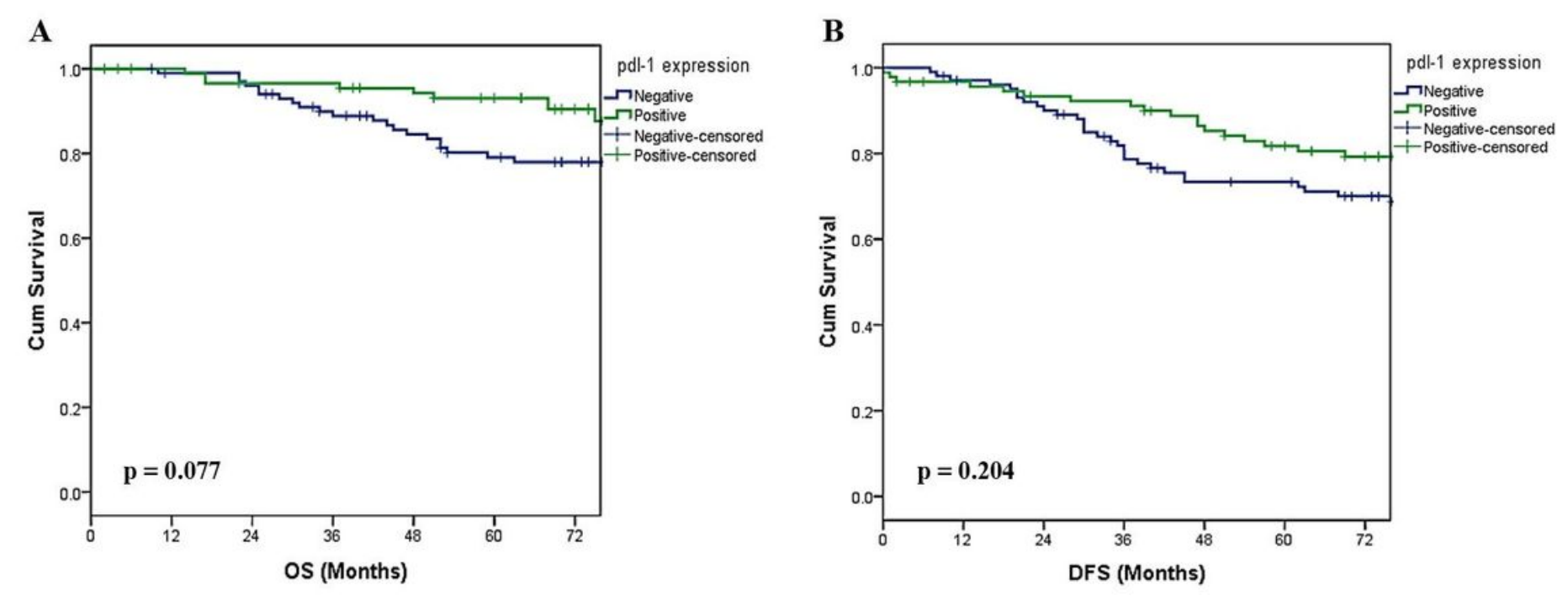


\section{Figure 3}

Kaplan-Meier survival analysis according to PD-L1 expression in breast cancer patients. (A) OS curves in patients with negative and positive PD-L1 expression. (B) DFS curves in patients with negative and positive PD-L1 expression.

$\mathbf{A}$

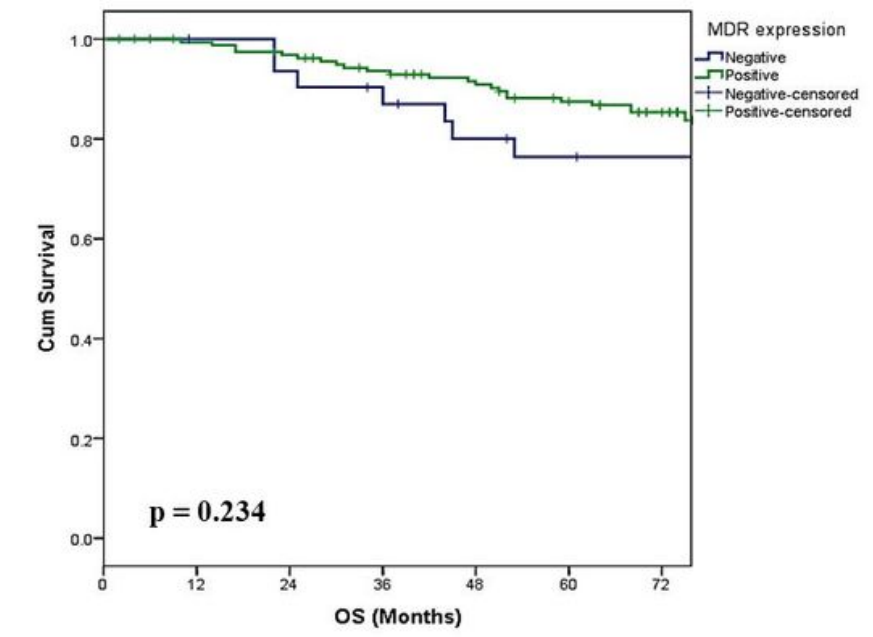

B

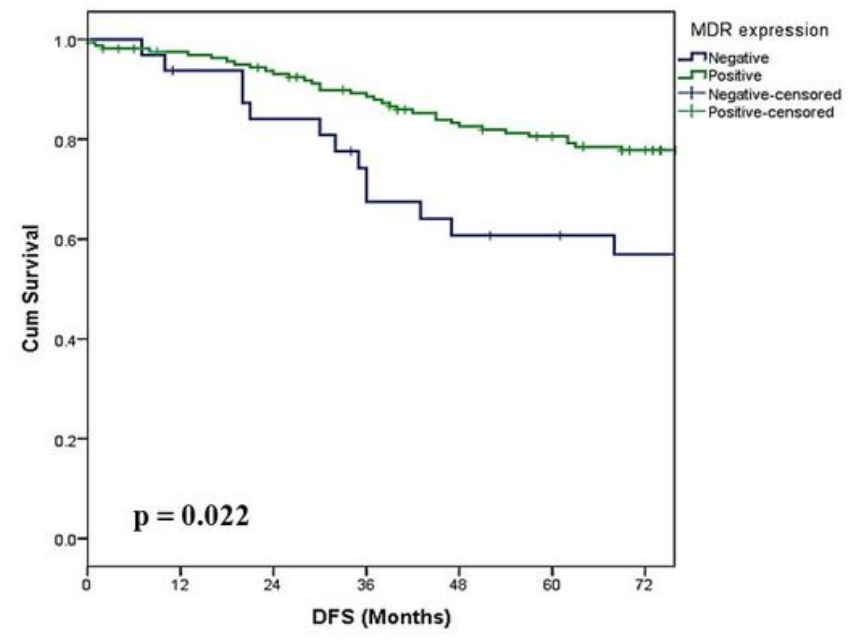

\section{Figure 4}

Kaplan-Meier survival analysis according to MDR1 expression in breast cancer patients. (A) OS curves in patients with negative and positive MDR1 expression. (B) DFS curves in patients with negative and positive MDR1 expression. 